\title{
Losartan modulates muscular capillary density and reverses thiazide diuretic-exacerbated insulin resistance in fructose-fed rats
}

\author{
Qi Guo ${ }^{1}$, Takefumi Mori ${ }^{1}$, Yue Jiang ${ }^{1}$, Chunyan $\mathrm{Hu}^{1}$, Yusuke Ohsaki ${ }^{1}$, Yoshimi Yoneki ${ }^{1}$, Takashi Nakamichi ${ }^{1}$, \\ Susumu Ogawa ${ }^{2}$, Hiroshi Sato ${ }^{1}$ and Sadayoshi Ito ${ }^{1}$
}

The renin-angiotensin system (RAS) is involved in the pathogenesis of insulin sensitivity (IS). The role of RAS in insulin resistance and muscular circulation has yet to be elucidated. Therefore, this study sought to determine the mechanisms of angiotensin II receptor blockers (ARBs) and/or diuretics on IS and capillary density (CD) in fructose-fed rats (FFRs). SpragueDawley rats were fed either normal chow (control group) or fructose-rich chow for 8 weeks. For the last 4 weeks, FFRs were allocated to four groups: an FFR group and groups treated with the thiazide diuretic hydrochlorothiazide (HCTZ), with the ARB losartan, or both. IS was evaluated by the euglycemic hyperinsulinemic glucose clamp technique at week 8 . In addition, CD in the extensor digitorum longus muscle was evaluated. Blood pressure was significantly higher in the FFRs than in the controls. HCTZ, losartan and their combination significantly lowered blood pressure. IS was significantly lower in the FFR group than in the controls and was even lower in the HCTZ group. Losartan alone or combined with HCTZ significantly increased IS. In all cases, IS was associated with muscular CD, but not with plasma adiponectin or lipids. These results indicate that losartan reverses HCTZ-exacerbated insulin resistance, which can be mediated through the modulation of muscular circulation in rats with impaired glucose metabolism.

Hypertension Research (2012) 35, 48-54; doi:10.1038/hr.2011.140; published online 8 September 2011

Keywords: angiotensin II receptor blocker; capillary density; insulin sensitivity; skeletal muscle; thiazide diuretic

\section{INTRODUCTION}

Recently, insulin resistance and hyperinsulinemia have been shown to be common in patients with essential hypertension or metabolic syndrome. ${ }^{1,2}$ These impairments of glucose metabolism are associated with a high risk of cardiovascular diseases, and improving insulin sensitivity (IS) has become recognized as an important component of cardiovascular risk reduction in patients with essential hypertension., ${ }^{2,3}$ Antihypertensive drugs are expected to have a beneficial effect on IS. It has been consistently shown that angiotensin II receptor blockers (ARBs) and angiotensin-converting enzyme inhibitors have beneficial effects on glucose metabolism, whereas the thiazide diuretics have an adverse effect, resulting in a worsening of IS. ${ }^{4}$ At the same time, the results of previous clinical studies examining the effects of ARBs on IS have been equivocal, with IS variously reported as being improved ${ }^{5}$ or unchanged. ${ }^{6}$ In addition, some recent clinical and animal studies have reported that the antihypertensive and cardiovascular protective effects of ARBs are strongly reinforced by concomitant administration of thiazides. ${ }^{7,8}$ It would thus be of great interest to determine whether and how ARBs modulate thiazide diuretic-exacerbated IS in hypertension and metabolic syndrome.
Skeletal muscle is considered a primary site of insulin resistance in essential hypertension. ${ }^{9}$ Euglycemic hyperinsulinemic glucose clamp studies have demonstrated that skeletal muscle accounts for over $80 \%$ of glucose disposal under hyperinsulinemic conditions in humans. Insulin-mediated glucose uptake has been shown to be correlated with capillary density (CD) $1{ }^{10} \mathrm{CD}$ in skeletal muscle has been shown to be decreased in patients with hypertension, ${ }^{11}$ non-insulin-dependent diabetes mellitus ${ }^{12}$ and obesity, ${ }^{13}$ as well as in experimental animal models. ${ }^{14-16}$ It has also been suggested that the diffusion distance from capillaries to muscle cells and/or some biochemical changes related to the diffusion distance contribute to a decrease in IS. ${ }^{17}$

Thus, we hypothesized that an ARB would reverse the thiazide diuretic-induced decrease in IS by modulating the muscle CD in hypertension. This study was designed to test this hypothesis by examining whether a thiazide diuretic (hydrochlorothiazide: HCTZ) or an ARB (losartan) alters IS in fructose-fed rats (FFRs), and if so, whether CD in skeletal muscle is involved in such changes. We selected the FFR model because a high-fructose diet in rats causes metabolic derangements, including hypertension and insulin resistance. ${ }^{18,19}$ Similarly, studies have demonstrated that the consumption of high

${ }^{1}$ Division of Nephrology, Endocrinology and Vascular Medicine, Tohoku University Graduate School of Medicine, Sendai, Japan and ${ }^{2} \mathrm{Health}$ Administration Center, Tohoku University, Sendai, Japan

Correspondence: Dr T Mori, Division of Nephrology, Endocrinology and Vascular Medicine, Tohoku University Graduate School of Medicine, 1-1 Seiryocho, Aoba-ku, Sendai 980-8574, Japan. 
amounts of fructose also causes hypertension and insulin resistance in humans. $^{20}$

\section{METHODS}

\section{General protocol}

Six-week-old male Sprague-Dawley rats (SLC, Shizuoka, Japan) were housed in a controlled temperature $\left(24^{\circ} \mathrm{C}\right)$ room with a 12-h light-dark cycle. All procedures were in accordance with the National Institutes of Health Guide for the Care and Use of Laboratory Animals, and the protocols were approved by the Animal Committee of Tohoku University. The rats were divided into two groups at the start of study: one fed standard chow containing $60 \%$ starch, $5 \%$ fat and $21 \%$ protein (Oriental Yeast, Tokyo, Japan; control; $n=10$ ) and the other fed fructose-rich chow containing $60 \%$ fructose, $5 \%$ fat and $21 \%$ protein (F2HFrD; Oriental Yeast; FFR; $n=33$ ) for 8 weeks. For the last 4 weeks, the FFRs were allocated to four groups: the FFR group (FFR; $n=9$ ), HCTZ (Merck, Whitehouse Station, NJ, USA) group (FFR+HCTZ; $n=9$ ), losartan (Merck) group (FFR+LOS; $n=7)$ and HCTZ plus losartan group (FFR+HCTZ+LOS; $n=8)$. HCTZ dissolved in $0.5 \%$ carboxymethylcellulose was administered by gavage daily at a dose of $80 \mathrm{mg} \mathrm{kg}^{-1} \mathrm{day}^{-1}$ in the FFR+HCTZ and FFR + HCTZ+LOS groups. Because one aim of the study was to examine the effect of losartan on IS exacerbated by HCTZ, we selected the highest dosage of HCTZ that has been commonly used in other rat studies ${ }^{8,21}$ to determine the maximum adverse effect on glucose metabolism. Losartan dissolved in water was given by gavage daily at a dose of $10 \mathrm{mg} \mathrm{kg}^{-1} \mathrm{day}^{-1}$ in the FFR+LOS and FFR+HCTZ+LOS groups. Rats were pair-fed to ensure equivalent caloric intake, thereby avoiding the influence of different food volumes on metabolic abnormalities. Body weight was measured weekly. Systolic blood pressure (SBP) was measured every week from 6-14 weeks of age in conscious rats by the indirect tail-cuff method (Model MK-2000A; Muromachi, Tokyo, Japan).

\section{Surgical procedures and drawing blood}

At the age of 14 weeks, after an overnight fast and under ether anesthesia, the rats were implanted with an arterial catheter (PE 100, Becton Dickinson, Sparks, MD, USA) and venous catheter (PE 20), each filled with heparinized saline $\left(100 \mathrm{IU} \mathrm{ml}^{-1}\right)$, into the left carotid artery and right jugular vein, respectively. The free ends of these catheters were brought subcutaneously to the back of the neck. During surgery, a $0.5 \mathrm{ml}$ blood sample was collected from the left carotid artery for biochemical analysis in all rats. Serum triglycerides were measured by a standard autoanalysis technique (Synchron-CX-3; Beckman Coulter, Fullerton, CA, USA). Serum adiponectin levels were measured using the enzyme-linked immunosorbent assay kit (Otsuka Pharmaceutical, Tokyo, Japan). The rats were returned to their individual cages and allowed to recover for 3 days after surgery.

\section{Euglycemic hyperinsulinemic glucose clamp technique}

After overnight fasting, conscious rats were examined for IS by a euglycemic hyperinsulinemic glucose clamp technique, as described previously. ${ }^{22,23}$ Briefly, before the start of the glucose clamp, fasting blood glucose was measured by a blood glucose test meter (A790820; GUNZE, Kyoto, Japan). An initial bolus of insulin ( $25 \mathrm{mU} \mathrm{kg}^{-1}$ of Humalin R, U-100; Eli Lilly Japan, Kobe, Japan) was infused through a venous catheter, and this step was followed by a constant infusion of insulin at a rate of $4 \mathrm{mU} \mathrm{kg}^{-1} \mathrm{~min}$ for $147 \mathrm{~min}$. During the glucose clamp, $12.5 \%$ glucose solution was infused as required to maintain the blood glucose at the fasting level. A volume of $10 \mu \mathrm{l}$ samples of arterial blood was collected through an arterial catheter at 7-min intervals for the determination of blood glucose. The average rate of glucose infusion $\left(\mathrm{mg} \mathrm{kg}^{-1} \mathrm{~min}^{-1}\right)$ for the last $35 \mathrm{~min}$ was taken as an index of IS (M value).22,23

\section{Tissue preparation and histological examination}

After the IS test, the rats were killed by intraperitoneal injection of pentobarbital $\left(100 \mathrm{mg} \mathrm{kg}^{-1}\right)$. The extensor digitorum longus (EDL) muscle was rapidly dissected and weighed. Each EDL muscle was sliced transversally in the midbelly region into 6-mm sections. These samples were rapidly frozen in isopentane cooled by dry ice and stored at $-80^{\circ} \mathrm{C}$ until use. Serial transverse cross-sections ( $10 \mu \mathrm{m}$ thick) near the mid-belly portion of the EDL were cut in a microtome cryostat at $-22^{\circ} \mathrm{C}$, mounted on glass slides and air-dried. CD was determined by the methods described previously. ${ }^{22}$ The capillary-to-fiber ratio $(\mathrm{C} / \mathrm{F})$ and $\mathrm{CD}$ were estimated using an image processing software package (WinROOF ver. 5.0; Mitani Corporation, Tokyo, Japan). For each muscle, at least 200 fibers and their associated capillaries were measured using the maximal number of non-overlapping fields.

\section{Data analysis}

All results are expressed as means \pm s.e.m. All data analyses were performed by Bonferroni/Dunn testing for multiple comparisons after one-way analysis of variance. Pearson's correlation coefficient and regression analysis were used to compare the relationship between $\mathrm{M}$ values and $\mathrm{CD}$ or $\mathrm{C} / \mathrm{F}$. To identify determinants of change in $\mathrm{M}$ values, we performed multiple stepwise regression analysis to compare the relationship between $\mathrm{M}$ values as the dependent variables and five variables $(\mathrm{CD}$ or $\mathrm{C} / \mathrm{F}$ and $\mathrm{SBP}, \mathrm{BW}$, serum adiponectin and triglycerides) as independent variables. Values of $P<0.05$ were considered to indicate statistical significance.

\section{RESULTS}

\section{Blood pressure}

Rats were pair-fed to ensure equivalent caloric intake throughout the experimental period. However, in the first 4 weeks, the food volume in the control rats was actually greater than that in the FFR groups; thus, we had to restrict the food volume in the control rats to achieve caloric equivalence among the groups. However, for the last 4 weeks, the food volume in the FFR+HCTZ+LOS rats was the smallest among the groups, such that we had to restrict the food volume in the control, FFR, FFR+LOS and FFR+HCTZ groups. Therefore, the SBP in FFRs progressively increased throughout the first 4 weeks, but the SBP was not significantly changed during the last 4 weeks in FFRs, as shown in Figure 1. HCTZ alone, losartan alone, and the two drugs in combination completely attenuated the development of hypertension after the 4 -week treatment. In addition, the SBP in the FFR+HCTZ+LOS rats at weeks 6,7 and 8 of the experimental period was lowest among the five groups.

\section{Insulin sensitivity}

Figure 2 shows the time course of the blood glucose level (upper panel), insulin infusion rate (middle panel) and glucose infusion rate (lower panel) of the glucose clamp in each group. Steady-state blood

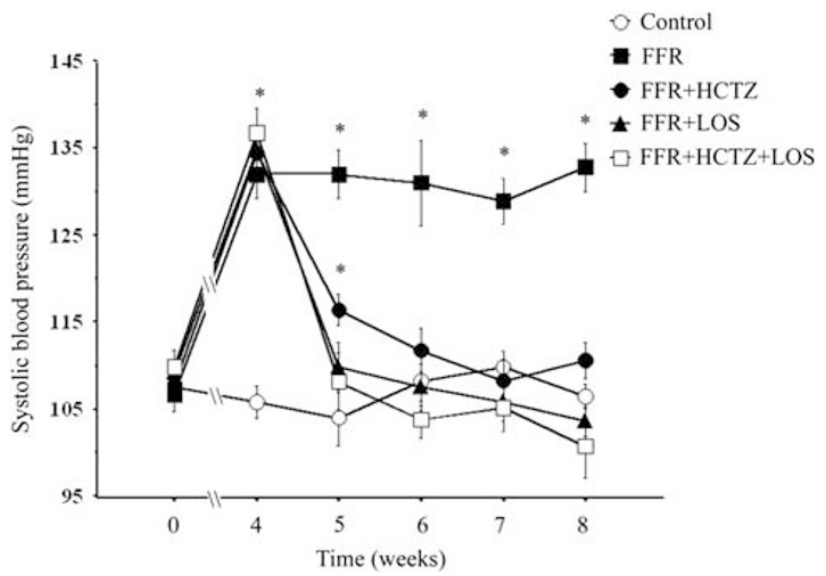

Figure 1 Sequential systolic blood pressure values during the 8-week experimental period in the five groups: control $(n=10)$, normal diet group; fructose-fed rat (FFR) ( $n=9)$, fructose-fed rats group; FFR+HCTZ $(n=9)$, fructose-fed rats and hydrochlorothiazide group; FFR+LOS ( $n=7)$, fructosefed rats and losartan group and FFR+HCTZ+LOS $(n=8)$, fructose-fed rats and hydrochlorothiazide plus losartan group. Data are the means \pm s.e.m. ${ }^{*} P<0.01$ vs. control. 

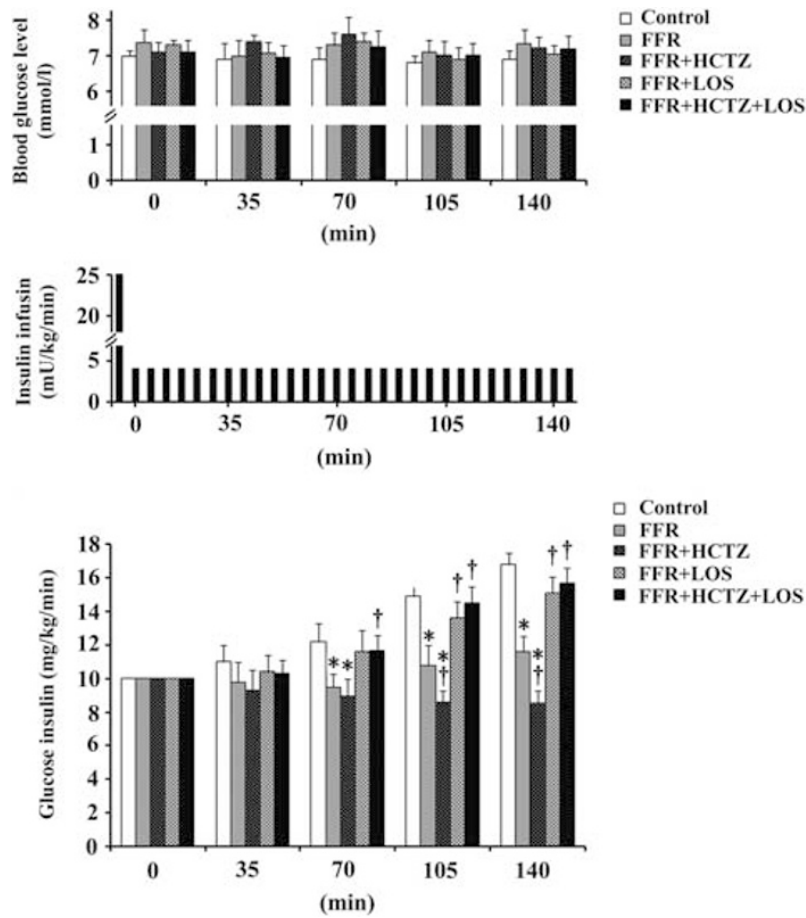

Figure 2 Time course of blood glucose level (upper panel), insulin infusion rate (middle panel) and glucose infusion rate (lower panel) of the glucose clamp in five groups: control $(n=10)$, normal diet group; FFR $(n=9)$, fructose-fed rats group; FFR+HCTZ $(n=9)$, fructose-fed rats and hydrochlorothiazide group; FFR+LOS $(n=7)$, fructose-fed rats and losartan group and FFR+HCTZ+LOS $(n=8)$, fructose-fed rats and hydrochlorothiazide plus losartan group. Data are the means \pm s.e.m. ${ }^{*} P<0.05$ vs. control; $\dagger P<0.05$ vs. FFR.

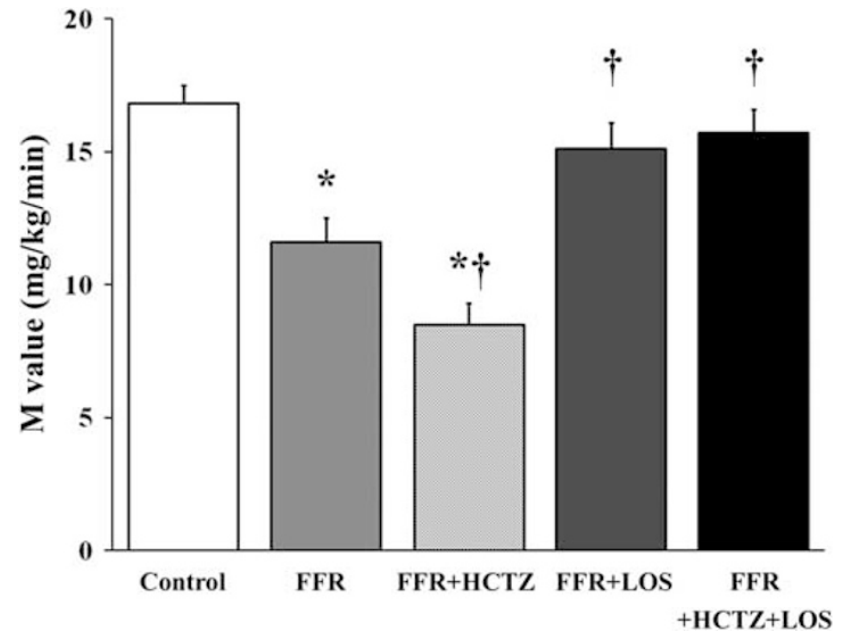

Figure 3 Comparisons of the index of insulin sensitivity ( $M$ value) in the five groups: control $(n=10)$, normal diet group; FFR $(n=9)$, fructose-fed rats group; FFR+HCTZ $(n=9)$, fructose-fed rats and hydrochlorothiazide group; FFR+LOS ( $n=7)$, fructose-fed rats and losartan group and FFR+HCTZ+LOS $(n=8)$, fructose-fed rats and hydrochlorothiazide plus losartan group. Data are the means \pm s.e.m. ${ }^{*} P<0.01$ vs. control; ${ }^{\dagger} P<0.01$ vs. FFR.

glucose levels during the glucose clamp were similar in the five experimental groups. The mean coefficient of variation $(\%)=\mathrm{SD} /$ mean $\times 100$ ) of the plasma glucose level during the clamps in the five
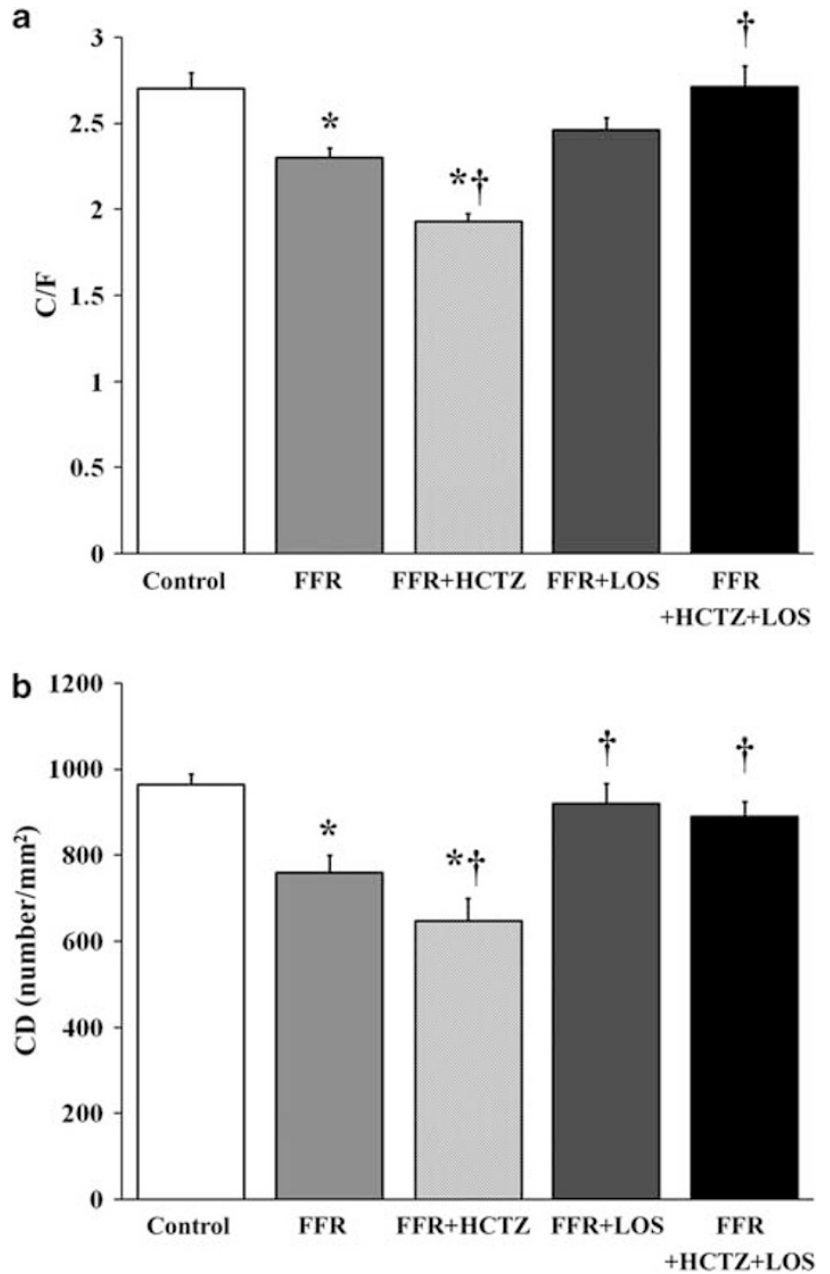

Figure 4 Comparisons of the capillary-to-fiber ratio (C/F) (a) and capillary density (CD) (b) in the five groups: control $(n=10)$, normal diet group; FFR $(n=9)$, fructose-fed rats group; FFR $+\mathrm{HCTZ}(n=9)$, fructose-fed rats and hydrochlorothiazide group; FFR+LOS ( $n=7)$, fructose-fed rats and losartan group and FFR+HCTZ+LOS $(n=8)$, fructose-fed rats and hydrochlorothiazide plus losartan group. Data are the means \pm s.e.m. ${ }^{*} P<0.01$ vs. control; $\dagger P<0.05$ vs. FFR.

experimental groups was 3\%. The $\mathrm{M}$ values in the five groups are shown in Figure 3. $\mathrm{M}$ values were significantly lower in the FFR groups $\left(11.6 \pm 0.9 \mathrm{mg} \mathrm{kg}^{-1} \mathrm{~min}^{-1}\right)$ than in the control group $\left(16.8 \pm 0.7 \mathrm{mg} \mathrm{kg}^{-1} \mathrm{~min}^{-1}\right)$. HCTZ further reduced the $\mathrm{M}$ values in the FFR+HCTZ group $\left(8.5 \pm 0.8 \mathrm{mg} \mathrm{kg}^{-1} \mathrm{~min}^{-1}\right)$ to less than those of the FFR group. However, losartan significantly increased the $M$ values in the FFR+LOS $\left(15.1 \pm 0.9 \mathrm{mg} \mathrm{kg}^{-1} \mathrm{~min}^{-1}\right)$ and FFR+HCTZ+LOS (15.7 $\pm 0.9 \mathrm{mg} \mathrm{kg}^{-1} \mathrm{~min}^{-1}$ ) groups compared with those of the FFR group.

\section{$\mathrm{CD}$ and regression analyses}

The effects of treatment on $\mathrm{C} / \mathrm{F}$ and $\mathrm{CD}$ are shown in Figure 4. The C/ $\mathrm{F}$ and $\mathrm{CD}$ in the FFR groups were significantly lower than in the control group. The CD in the FFR+LOS group and the $\mathrm{C} / \mathrm{F}$ and $\mathrm{CD}$ in the FFR+HCTZ+LOS group were significantly higher than those in the FFR group. Although it did not reach the level of significance $(P=0.12)$, the $\mathrm{C} / \mathrm{F}$ tended to be higher in the FFR+LOS group than in the FFR group. However, the C/F and CD in the FFR+HCTZ group were significantly lower than those in the FFR group (Figure 5). 


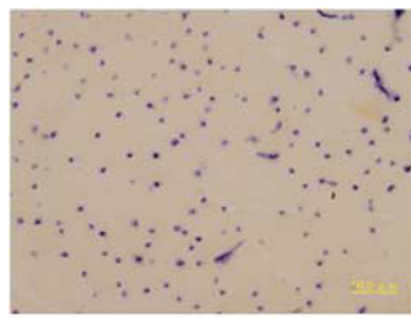

Control

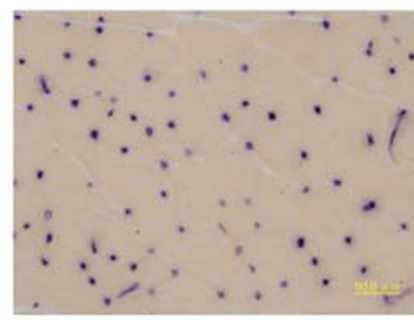

FFR

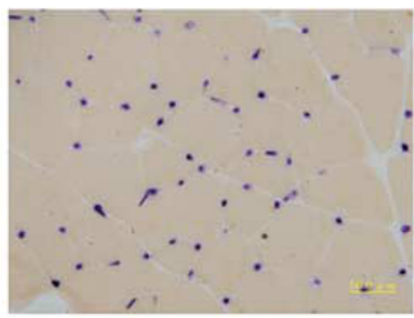

FFR+HCTZ

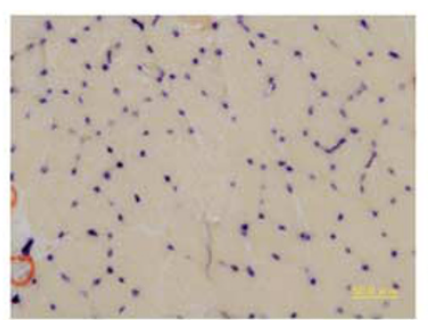

FFR+LOS

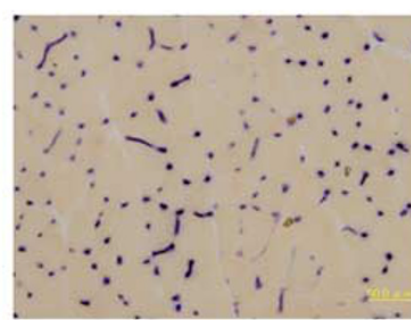

FFR+HCTZ+LOS

Figure 5 Representative cross-sections of extensor digitorum longus muscle in the five groups. The capillaries stained blue. Scale bar $50 \mu \mathrm{m}$. Control, normal diet group; FFR, fructose-fed rats group; FFR+HCTZ, fructose-fed rats and hydrochlorothiazide group; FFR+LOS, fructose-fed rats and losartan group and $\mathrm{FFR}+\mathrm{HCTZ}+\mathrm{LOS}$, fructose-fed rats and hydrochlorothiazide plus losartan group.
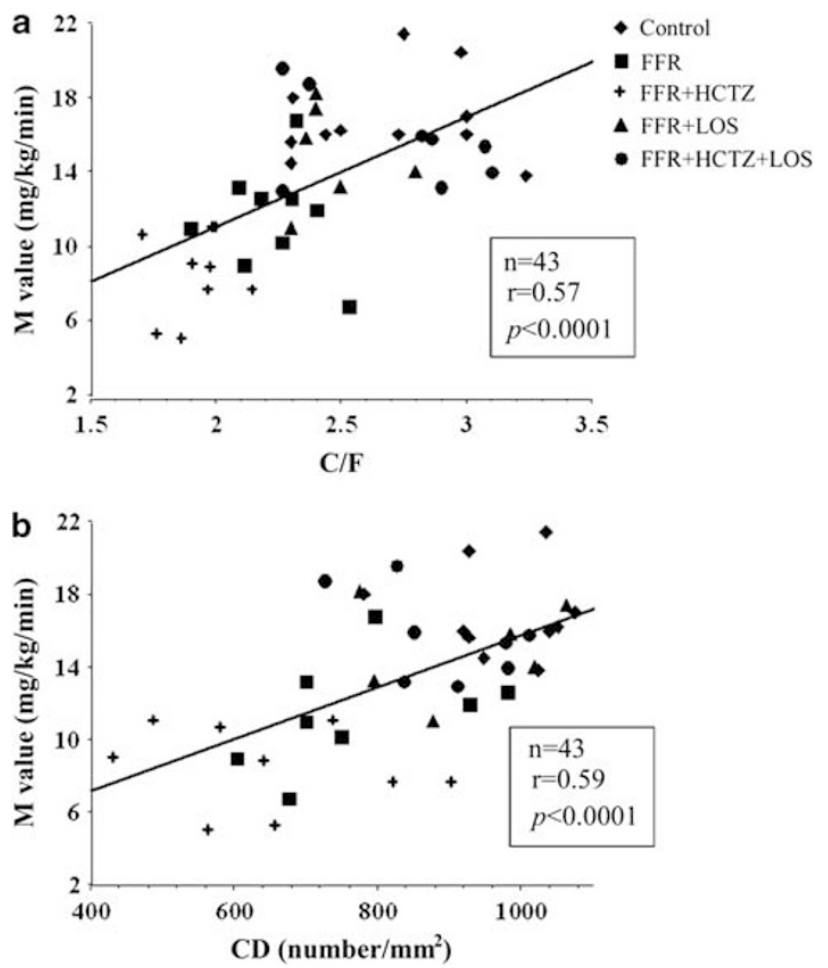

Figure 6 Correlation between $M$ value and capillary-to-fiber ratio (C/F) (a) and capillary density (CD) (b).

There were significantly positive correlations between the $M$ values and $\mathrm{C} / \mathrm{F}$ (Figure $6 \mathrm{a}$ ) and $\mathrm{CD}$ (Figure $6 \mathrm{~b}$ ). In addition, we performed multiple stepwise regression analysis to compare the relationship between $M$ values as dependent variables, five variables with $C D$ (CD, SBP, BW, serum adiponectin and triglycerides) as independent variables and $M$ values and five variables with $C / F(C / F, S B P, B W$,
Table 1 Body weight (BW) and serum triglyceride and adiponectin levels at week 8 of the experimental period

\begin{tabular}{lccc}
\hline Groups $(n)$ & $B W(g)$ & $\begin{array}{c}\text { Serum triglyceride } \\
\left(\mathrm{mgdl}^{-1}\right)\end{array}$ & $\begin{array}{c}\text { Serum adiponectin } \\
\left(\mu g \mathrm{ml}^{-1}\right)\end{array}$ \\
\hline Control (10) & $390 \pm 7$ & $64.6 \pm 14.6$ & $3.44 \pm 0.52$ \\
FFR (9) & $388 \pm 9$ & $86.0 \pm 11.3$ & $2.42 \pm 0.18^{*}$ \\
FFR+HCTZ (9) & $374 \pm 9$ & $96.0 \pm 23.6$ & $1.13 \pm 0.12^{* \dagger}$ \\
FFR+LOS (7) & $384 \pm 5$ & $95.5 \pm 12.2$ & $2.12 \pm 0.23^{*}$ \\
FFR+HCTZ+LOS (8) & $378 \pm 8$ & $97.3 \pm 15.8$ & $1.01 \pm 0.08^{* \dagger}$ \\
\hline
\end{tabular}

Abbreviations: Control, normal diet group; FFR, fructose-fed rats group; FFR+HCTZ, fructose-fed rats and hydrochlorothiazide group; FFR+LOS, fructose-fed rats and losartan group; FFR+HCTZ+LOS, fructose-fed rats and hydrochlorothiazide plus losartan group. Data are the means \pm s.e.m.

${ }^{*} P<0.01$ vs. control; ${ }^{\dagger} P<0.01$ vs. FFR.

serum adiponectin and triglycerides), respectively. The data indicated that the $\mathrm{M}$ values were predicted by the $\mathrm{CD}\left(R^{2}=0.35, F=21.7\right.$, $P<0.0001)$ and $\mathrm{C} / \mathrm{F}\left(R^{2}=0.33, F=20.5, P<0.0001\right)$, respectively, but not by SBP, BW, serum adiponectin or triglycerides, at week 8 in all rats.

\section{Body weight and serum compositions}

There were no significant intergroup differences in BW or serum triglycerides at week 8 (Table 1). The serum adiponectin level in the FFR groups was significantly lower than that in the control group. The serum adiponectin levels in the FFR+HCTZ and FFR+HCTZ+LOS groups were significantly lower than those in the FFR group. However, there were no statistically significant differences in the serum adiponectin levels between the FFR+HCTZ and FFR+HCTZ+LOS groups or between the FFR and FFR+LOS groups.

\section{DISCUSSION}

This study confirmed previous reports that a fructose-rich diet reduces IS in normal rats and leads to hypertension. ${ }^{18,19,24}$ The CD of skeletal muscle was lower in FFRs than in the controls, and HCTZ further 
decreased IS and CD in FFRs, although it has significant hypotensive effects. However, treatment with losartan recovered IS and CD in both the FFR and the FFR+HCTZ groups to the level seen in the control rats. Multiple regression analysis indicated that the $M$ value, a marker of IS, was predicted by CD in the EDL independent of SBP, BW and serum adiponectin and triglycerides in this study. These results indicate that $\mathrm{CD}$ has a role in the modulation of IS by a fructose diet and HCTZ and/or losartan treatment. To the best of our knowledge, this study is the first to investigate CD in FFRs after treatment with HCTZ and/or losartan.

\section{Effects of thiazide diuretics and ARBs on IS}

It has been shown that high doses of thiazide diuretics have an adverse effect on glucose metabolism. Consistent with the previous study, ${ }^{18}$ the results in this study demonstrated that HCTZ significantly worsened the fructose-induced decrease in IS in FFRs. Conversely, the present findings showed that losartan significantly improved IS in FFRs. Several previous studies failed to demonstrate any losartaninduced improvement in IS in hypertensive or normotensive subjects $^{6,25}$ or in type 2 diabetic rats (IS was assessed by oral glucose tolerance test). ${ }^{26}$ Moan et al. ${ }^{27}$ found that losartan improved IS in patients with severe essential hypertension but had little effect on IS in those patients with mild essential hypertension. Although our recent results showed that the ARB olmesartan did not significantly improve (less effect) IS in spontaneously hypertensive rats, ${ }^{22}$ which was consistent with our present results, Higashiura et al. ${ }^{28}$ reported that olmesartan significantly improved IS in FFRs (IS was assessed by the euglycemic hyperinsulinemic glucose clamp technique). These different findings concerning the effects of ARBs on IS may be related to differences in the subjects or rat strains, as well as differences in the measurement methods for IS analysis. In our present and previous studies, we used the euglycemic hyperinsulinemic clamp technique, a gold standard method for investigating and quantifying IS, because it measures the amount of glucose necessary to compensate for an increased insulin level without causing hypoglycemia. ${ }^{29}$ This technique is a better evaluation method than other methods, such as the oral glucose tolerance test. Although the mechanisms by which ARBs improve IS are not fully understood, a possible mechanism by which ARBs improve IS is through increased cellular cyclic adenosine $3^{\prime}, 5^{\prime}$-monophosphate levels and the production of insulin-like growth factor-I. ${ }^{30}$ In addition, losartan might improve IS by activating insulin-sensitizing peroxisome proliferators-activated receptor (PPAR) $-\gamma \cdot{ }^{31}$ However, the ability of other ARBs (such as olmesartan) to activate PPAR- $\gamma$ receptors tested in this setting was less. ${ }^{32}$

\section{Capillary density in skeletal muscle is decreased in insulin-resistant rats}

Several reports have shown the relationship between skeletal muscle CD and IS/resistance in humans. ${ }^{11-13,33-35}$ Likewise, rodent studies have demonstrated a direct effect of capillarization on insulin action in skeletal muscles. ${ }^{14-16,36,37}$ A decrease in CD is associated with a longer diffusion distance between the nutritional blood vessels and the skeletal muscle cells. This change would impede the delivery of glucose to the muscle cells and thereby decrease IS. ${ }^{17}$ In this study, there was a significant positive correlation between IS and CD values in the EDL muscle, and IS was predicted by CD in the EDL independent of SBP, $\mathrm{BW}$, serum adiponectin and triglycerides in all the rats. Thus, fructose, HCTZ and losartan affected IS, at least in part by changing the CD.

In this study, CD in the EDL was significantly lower in FFRs than in the controls. However, Takada et al. ${ }^{19}$ reported that the CD in the soleus muscle in FFRs was not altered by fructose-rich chow. The reason for the disparate results between the previous study and this study is not clear, but differences in the kind of skeletal muscle may be involved. Skeletal muscle consists of type I, type IIa and type IIb fibers. Type I and type IIa fibers have high capillary densities, whereas type IIb fibers have a low $\mathrm{CD}^{38,39}$ It is thought that an increase in type IIb fibers contributes to the reduction in CD. As reported by Higashiura et al. ${ }^{28}$ the percentage of type IIb fibers in the soleus muscle is $<1 \%$, and thus there is no significant difference in the amount of type IIb fibers in the soleus muscle between FFRs and control rats. However, there are a significant decrease in the percentage of type I fibers and a significant increase in the percentage of type IIa fibers in FFRs relative to controls. The EDL muscle has more type IIb fibers than the soleus muscle, so it may be easier to detect differences in CD based on changes in type IIb fibers in the EDL than in the soleus muscle. Thus, we evaluated CD in the EDL in this study, and our results showed that a fructose-rich diet in normal rats reduced CD in the EDL. Similarly, our results showed that the CD in skeletal muscle decreased in an experimental animal model of insulin resistance. ${ }^{14-16}$ Frisbee et al. ${ }^{15}$ suggested that microvessel rarefaction in the skeletal muscles of obese Zucker rats manifesting insulin resistance did not depend on an elevated mean arterial pressure and that other factors associated with insulin resistance may underlie the progressive reduction in skeletal muscle microvessel density in these animals. These results suggest that there is an association between IS and CD in skeletal muscle, although the mechanisms are not clearly understood. Ellis et al. ${ }^{16}$ found that insulin attenuates the $\mathrm{O}_{2}$-dependent release of adenosine triphosphate from the red blood cells and suggested that this defect in red blood cell physiology could contribute to a failure in the regulation of the $\mathrm{O}_{2}$ supply to meet the demand in the EDL in a model of insulin resistance using diabetic fatty Zucker rats fed a high-fat diet. In addition, a high fructose diet also causes mitochondrial dysfunction in skeletal muscle, ${ }^{40,41}$ and mitochondrial dysfunction has been associated with insulin resistance in skeletal muscle. ${ }^{42}$ Brownlee suggested that mitochondrial dysfunction occurs as a 'unifying mechanism' for microvascular and macrovascular complications through reactive oxygen species production. ${ }^{43}$ Hyperglycemia induced by endothelial dysfunction is inhibited by blocking ROS production from mitochondria and by overexpression of uncoupling proteins or manganese superoxide dismutase. ${ }^{43}$ Furthermore, endothelial NO synthase in vascular endothelial cells seems to have an important role in insulin-stimulated NO production and vasodilation. ${ }^{44}$

\section{Mechanisms of thiazide diuretics and ARBs on capillary density in skeletal muscle}

Capillary rarefaction associated with hypertension has been considered a form of structural autoregulation, reflecting the long-term adaptation of the microcirculation to elevated blood pressure. It has been shown that vasodilatation and increased blood flow promote angiogenesis in skeletal muscles. ${ }^{45}$ Thus, losartan may increase the CD through its vasodilator action or hypotensive effect. ${ }^{46}$ In addition to the vasodilator or hypotensive effect, the proangiogenic effect of losartan may also be mediated by the following mechanism: ARB blocks AT1 receptors, whereas unbound angiotensin II stimulates AT2 receptors, which in turn increase angiogenic factors, such as vascular endothelial growth factor receptors, Tie-2 expression and the angiopoietin-1/angiopoietin-2 ratio. ${ }^{47}$ In addition, You et al. ${ }^{48}$ reported that losartan administration resulted in an improvement in hindlimb ischemia-induced capillary rarefaction, and this improvement was associated with a restoration of progenitor cell-related function in spontaneously hypertensive rat. In contrast, although HCTZ and 
losartan had similar hypotensive effects in this study, treatment with HCTZ decreased the $\mathrm{CD}$, indicating that blood pressure was not involved in the changes in $\mathrm{CD}$ and IS. A possible mechanism by which HCTZ decreased the CD is that HCTZ reduced blood pressure through decreased cardiac output, ${ }^{49}$ and decreased cardiac output associated with a decreased peripheral blood flow would contribute to the induction of capillary rarefaction in skeletal muscle. ${ }^{45}$ Capillary rarefaction would enable the tissue blood flow to be regulated without consumption of the energy necessary for active vasoconstriction. ${ }^{14}$

\section{Serum adiponectin cannot mediate the beneficial effects of ARBs on IS in FFR}

Conversely, consistent with previous reports, ${ }^{50,51}$ the results in this study indicated that the decreases in IS induced by a fructose-rich diet or administration of HCTZ are associated with decreased serum adiponectin, a protein with levels that are known to increase with existing PPAR- $\gamma$ agonists and to correlate with IS. ${ }^{52}$ However, in this study, losartan-increased IS in the FFR+LOS and FFR+HCTZ+LOS groups was not coupled with increased serum adiponectin levels. Recently, several studies, but not all, have revealed that ARBs improved hypertension with increasing adiponectin. ${ }^{24,51}$ Consistent with our present results, Kamari et al. ${ }^{24}$ reported that telmisartan, an ARB with greater PPAR- $\gamma$ activity, effectively improved fructose-induced hypertension, hyperinsulinemia and hypertriglyceridemia, but did not affect serum adiponectin in FFRs. In addition, Sharabi et al. ${ }^{53}$ showed in FFRs that the PPAR- $\gamma$ agonist rosiglitazone improved the metabolic profile to a degree similar to telmisartan, but with increases in serum adiponectin levels and gene expression. Therefore, it is unlikely that adiponectin could always mediate the beneficial effects of ARBs on IS in FFRs.

\section{Pair-feeding can eliminate effects of food volume on BW and serum triglyceride}

IS is negatively correlated with BW. However, the FFR model is associated with weight loss, although it is a commonly used model that mimics human metabolic syndrome in many respects, including hypertension and insulin resistance. ${ }^{19}$ In addition, food volume can also influence glucose, insulin and triglyceride levels. In this study, therefore, all rats were pair-fed to eliminate these effects related to food volume. There were no significant intergroup differences in BW or serum triglycerides at week 8 of this study. We therefore concluded that the intergroup differences in IS were not related to differences in food volume.

In summary, we have demonstrated that HCTZ decreased IS, but losartan ameliorated the HCTZ-induced decrease in IS in FFRs, and these changes in IS were at least partially attributable to a modulation of $\mathrm{CD}$ in skeletal muscles. If these findings are confirmed in humans, then the combination of losartan and HCTZ may be recommended for the treatment of hypertensive subjects with insulin resistance, without considering the adverse effect of thiazide diuretics on glucose metabolism.

\section{CONFLICT OF INTEREST}

The authors declare no conflict of interest.

\section{ACKNOWLEDGEMENTS}

We thank Kiyomi Kisu for her expert technical assistance. This work was supported by Grants-in-Aid for Scientific Research from the Ministry of Education, Culture, Sports, Science and Technology of Japan (nos. 17590181 and 20590970).
1 Lender D, Arauz-Pacheco C, Adams-Huet B, Raskin P. Essential hypertension is associated with decreased insulin clearance and insulin resistance. Hypertension 1997; 29: 111-114.

2 Fortuno A, Bidegain J, San Jose G, Robador PA, Landecho MF, Beloqui O, Diez J, Zalba G. Insulin resistance determines phagocytic nicotinamide adenine dinucleotide phosphate oxidase overactivation in metabolic syndrome patients. J Hypertens 2009; 27: 1420-1430.

3 DeFronzo RA. Insulin resistance, hyperinsulinemia, and coronary artery disease: a complex metabolic web. J Cardiovasc Pharmacol 1992; 20(Suppl 11): S1-S16.

4 Lithell HO. Effect of antihypertensive drugs on insulin, glucose, and lipid metabolism. Diabetes Care 1991; 14: 203-209.

5 Tomiyama H, Yambe M, Yamada J, Motobe K, Koji Y, Yoshida M, Shiina K, Yamashina A. Discrepancy between improvement of insulin sensitivity and that of arterial endothelial function in patients receiving antihypertensive medication. J Hypertens 2007; 25: 883-889.

6 Laakso M, Karjalainen L, Lempiainen-Kuosa P. Effects of losartan on insulin sensitivity in hypertensive subjects. Hypertension 1996; 28: 392-396.

7 Lacourciere Y, Poirier L. Antihypertensive effects of two fixed-dose combinations of losartan and hydrochlorothiazide versus hydrochlorothiazide monotherapy in subjects with ambulatory systolic hypertension. Am J Hypertens 2003; 16: 1036-1042.

8 Zhou X, Matavelli LC, Ono H, Frohlich ED. Superiority of combination of thiazide with angiotensin-converting enzyme inhibitor or AT1-receptor blocker over thiazide alone on renoprotection in L-NAME/SHR. Am J Physiol Renal Physiol 2005; 289: F871-F879.

9 Capaldo B, Lembo G, Napoli R, Rendina V, Albano G, Sacca L, Trimarco B. Skeletal muscle is a primary site of insulin resistance in essential hypertension. Metabolism 1991; 40: 1320-1322.

10 James $D E$, Jenkins $A B$, Kraegen EW. Heterogeneity of insulin action in individual muscles in vivo: euglycemic clamp studies in rats. Am J Physiol 1985; 248: E567E574.

11 Hedman A, Reneland R, Lithell HO. Alterations in skeletal muscle morphology in glucose-tolerant elderly hypertensive men: relationship to development of hypertension and heart rate. J Hypertens 2000; 18: 559-565.

12 Marin P, Andersson B, Krotkiewski M, Bjorntorp P. Muscle fiber composition and capillary density in women and men with NIDDM. Diabetes Care 1994; 17: 382-386.

13 Lillioja S, Young AA, Culter CL, Ivy JL, Abbott WG, Zawadzki JK, Yki-Jarvinen H, Christin L, Secomb TW, Bogardus C. Skeletal muscle capillary density and fiber type are possible determinants of in vivo insulin resistance in man. J Clin Invest 1987; 80. 415-424.

14 Prewitt RL, Chen II, Dowell R. Development of microvascular rarefaction in the spontaneously hypertensive rat. Am J Physiol 1982; 243: H243-H251.

15 Frisbee JC. Hypertension-independent microvascular rarefaction in the obese Zucker rat model of the metabolic syndrome. Microcirculation 2005; 12: 383-392.

16 Ellis CG, Goldman D, Hanson M, Stephenson AH, Milkovich S, Benlamri A, Ellsworth ML, Sprague RS. Defects in oxygen supply to skeletal muscle of prediabetic ZDF rats. Am J Physiol Heart Circ Physiol 2010; 298: H1661-H1670.

17 Julius S, Gudbrandsson T, Jamerson K, Tariq Shahab S, Andersson O. The hemodynamic link between insulin resistance and hypertension. J Hypertens 1991; 9: 983-986.

18 Reungjui S, Roncal CA, Mu W, Srinivas TR, Sirivongs D, Johnson RJ, Nakagawa T. Thiazide diuretics exacerbate fructose-induced metabolic syndrome. J Am Soc Nephrol 2007; 18: 2724-2731.

19 Takada M, Ura N, Higashiura K, Murakami H, Togashi N, Shimamoto K. Effects of cilnidipine on muscle fiber composition, capillary density and muscle blood flow in fructose-fed rats. Hypertens Res 2001; 24: 565-572.

20 Faeh D, Minehira K, Schwarz JM, Periasamy R, Park S, Tappy L. Effect of fructose overfeeding and fish oil administration on hepatic de novo lipogenesis and insulin sensitivity in healthy men. Diabetes 2005; 54: 1907-1913.

21 Ono Y, Ono H, Frohlich ED. Hydrochlorothiazide exacerbates nitric oxide-blockade nephrosclerosis with glomerular hypertension in spontaneously hypertensive rats. J Hypertens 1996; 14: 823-828.

22 Guo Q, Minami N, Mori N, Nagasaka M, Ito O, Kurosawa H, Kanazawa M, Kohzuki M. Effects of antihypertensive drugs and exercise training on insulin sensitivity in spontaneously hypertensive rats. Hypertens Res 2008; 31: 525-533.

23 Guo Q, Mori T, Jiang Y, Hu C, Osaki Y, Yoneki Y, Sun Y, Hosoya T, Kawamata A, Ogawa S, Nakayama M, Miyata T, Ito S. Methylglyoxal contributes to the development of insulin resistance and salt sensitivity in Sprague-Dawley rats. J Hypertens 2009; 27 : 1664-1671.

24 Kamari Y, Harari A, Shaish A, Peleg E, Sharabi Y, Harats D, Grossman E. Effect of telmisartan, angiotensin II receptor antagonist, on metabolic profile in fructose-induced hypertensive, hyperinsulinemic, hyperlipidemic rats. Hypertens Res 2008; 31: 135-140.

25 Lerch M, Teuscher AU, Beissner P, Schneider M, Shaw SG, Weidmann P. Effects of angiotensin II-receptor blockade with losartan on insulin sensitivity, lipid profile, and endothelin in normotensive offspring of hypertensive parents. J Cardiovasc Pharmacol 1998; 31: 576-580.

26 Ishizawa K, Yoshizumi M, Tsuchiya K, Takishita E, Nakaya Y, Kishi K, Ebina Y, Houchi $\mathrm{H}$, Minakuchi K, Tamaki T. Effects of losartan in combination with or without exercise on insulin resistance in Otsuka Long-Evans Tokushima Fatty rats. Eur J Pharmacol 2001; 430: 359-367.

27 Moan A, Hoieggen A, Seljeflot I, Risanger T, Arnesen H, Kjeldsen SE. The effect of angiotensin II receptor antagonism with losartan on glucose metabolism and insulin sensitivity. J Hypertens 1996; 14: 1093-1097.

28 Higashiura K, Ura N, Takada T, Li Y, Torii T, Togashi N, Takada M, Takizawa H, Shimamoto $\mathrm{K}$. The effects of an angiotensin-converting enzyme inhibitor and an 
angiotensin II receptor antagonist on insulin resistance in fructose-fed rats. Am J Hypertens 2000; 13: 290-297.

29 DeFronzo RA, Tobin JD, Andres R. Glucose clamp technique: a method for quantifying insulin secretion and resistance. Am J Physiol 1979; 237: E214-E223.

30 Harada N, Shimozawa N, Okajima K. AT(1) receptor blockers increase insulin-like growth factor-I production by stimulating sensory neurons in spontaneously hypertensive rats. Transl Res 2009; 154: 142-152.

31 Kappert K, Tsuprykov O, Kaufmann J, Fritzsche J, Ott I, Goebel M, Bahr IN, Hassle PL, Gust R, Fleck E, Unger T, Stawowy P, Kintscher U. Chronic treatment with losartan results in sufficient serum levels of the metabolite EXP3179 for PPARgamma activation. Hypertension 2009; 54: 738-743.

32 Benson SC, Pershadsingh HA, Ho Cl, Chittiboyina A, Desai P, Pravenec M, Qi N, Wang J, Avery MA, Kurtz TW. Identification of telmisartan as a unique angiotensin II receptor antagonist with selective PPARgamma-modulating activity. Hypertension 2004; 43: 993-1002.

33 Hedman A, Berglund L, Essen-Gustavsson B, Reneland R, Lithell H. Relationships between muscle morphology and insulin sensitivity are improved after adjustment for intra-individual variability in 70-year-old men. Acta Physiol Scand 2000; 169: 125132.

34 Hedman A, Byberg L, Reneland R, Lithell HO. Muscle morphology, self-reported physical activity and insulin resistance syndrome. Acta Physiol Scand 2002; 175: 325-332.

35 Prior SJ, McKenzie MJ, Joseph LJ, Ivey FM, Macko RF, Hafer-Macko CE, Ryan AS. Reduced skeletal muscle capillarization and glucose intolerance. Microcirculation 2009; 16: 203-212.

36 Vollus GC, Bradley EA, Roberts MK, Newman JM, Richards SM, Rattigan S, Barrett EJ, Clark MG. Graded occlusion of perfused rat muscle vasculature decreases insulin action. Clin Sci 2007; 112: 457-466.

37 Rattigan S, Clark MG, Barrett EJ. Hemodynamic actions of insulin in rat skeletal muscle: evidence for capillary recruitment. Diabetes 1997; 46: 1381-1388.

38 Andersen P. Capillary density in skeletal muscle of man. Acta Physiol Scand 1975; 95 : 203-205.

39 Degens H, Turek Z, Hoofd LJ, Van't Hof MA, Binkhorst RA. The relationship between capillarisation and fibre types during compensatory hypertrophy of the plantaris muscle in the rat. J Anat 1992; 180(Part 3): 455-463.

40 Kannappan S, Anuradha CV. Insulin sensitizing actions of fenugreek seed polyphenols, quercetin \& metformin in a rat model. Indian J Med Res 2009; 129: 401-408.

41 Nagai Y, Nishio Y, Nakamura T, Maegawa H, Kikkawa R, Kashiwagi A. Amelioration of high fructose-induced metabolic derangements by activation of PPARalpha. Am J Physiol Endocrinol Metab 2002; 282: E1180-E1190.

42 Mogensen M, Sahlin K, Fernstrom M, Glintborg D, Vind BF, Beck-Nielsen H, Hojlund K. Mitochondrial respiration is decreased in skeletal muscle of patients with type 2 diabetes. Diabetes 2007; 56: 1592-1599.
43 Brownlee M. The pathobiology of diabetic complications: a unifying mechanism. Diabetes 2005; 54: 1615-1625.

44 Montagnani M, Chen H, Barr VA, Quon MJ. Insulin-stimulated activation of eNOS is independent of $\mathrm{Ca} 2+$ but requires phosphorylation by Akt at Ser(1179). J Biol Chem 2001; 276: 30392-30398.

45 Hudlicka 0 . Is physiological angiogenesis in skeletal muscle regulated by changes in microcirculation? Microcirculation 1998; 5: 7-23.

46 Gardiner SM, March JE, Kemp PA, Ballard SA, Bennett T. Regional hemodynamic effects of neutral endopeptidase inhibition and angiotensin (AT(1)) receptor antagonism alone or in combination in conscious spontaneously hypertensive rats. $J$ Pharmacol Exp Ther 2006; 319: 340-348.

47 Kitayama H, Maeshima Y, Takazawa Y, Yamamoto Y, Wu Y, Ichinose K, Hirokoshi K, Sugiyama $\mathrm{H}$, Yamasaki $\mathrm{Y}$, Makino $\mathrm{H}$. Regulation of angiogenic factors in angiotensin II infusion model in association with tubulointerstitial injuries. Am J Hypertens 2006; 19: 718-727.

48 You D, Cochain C, Loinard C, Vilar J, Mees B, Duriez M, Levy BI, Silvestre JS. Hypertension impairs postnatal vasculogenesis: role of antihypertensive agents. Hypertension 2008; 51 : 1537-1544.

49 Dahlof B, Hansson L. The influence of antihypertensive therapy on the structural arteriolar changes in essential hypertension: different effects of enalapril and hydrochlorothiazide. J Intern Med 1993; 234: 271-279.

50 Wang X, Hattori Y, Satoh H, Iwata C, Banba N, Monden T, Uchida K, Kamikawa Y, Kasai $\mathrm{K}$. Tetrahydrobiopterin prevents endothelial dysfunction and restores adiponectin levels in rats. Eur J Pharmacol 2007; 555: 48-53.

51 Koh KK, Quon MJ, Han SH, Lee Y, Kim SJ, Koh Y, Shin EK. Distinct vascular and metabolic effects of different classes of anti-hypertensive drugs. Int J Cardiol 2010; 140: 73-81.

52 Yang B, Brown KK, Chen L, Carrick KM, Clifton LG, McNulty JA, Winegar DA, Strum JC, Stimpson SA, Pahel GL. Serum adiponectin as a biomarker for in vivo PPARgamma activation and PPARgamma agonist-induced efficacy on insulin sensitization/lipid lowering in rats. BMC Pharmacol 2004; 4: 23.

53 Sharabi Y, Oron-Herman M, Kamari Y, Avni I, Peleg E, Shabtay Z, Grossman E, Shamiss A. Effect of PPAR-gamma agonist on adiponectin levels in the metabolic syndrome: lessons from the high fructose fed rat model. Am J Hypertens 2007; 20: 206-210.

This work is licensed under the Creative Commons Attribution-NonCommercial-No Derivative Works 3.0

Unported License. To view a copy of this license, visit http://creative commons.org/licenses/by-nc-nd/3.0 